\title{
Presença familiar no olhar existencial da pessoa com câncer: compreendendo o fenômeno à luz heideggeriana
}

The presence of the family in the existential outlook of cancer patients: understanding the phenomenon in the light of Heidegger

Presencia familiar en visión existencial de personas con cáncer: comprendiendo el fenómeno según fenomenología heideggeriana

Catarina Aparecida Sales ${ }^{1}$, Kelly Cristine Piolli ${ }^{2}$, Kesley de Oliveira Reticena ${ }^{3}$, Julia Wakiuchi ${ }^{4}$, Sonia Silva Marcon ${ }^{5}$ ${ }^{1}$ Enfermeira, Doutora em Enfermagem na Saúde do Adulto. Professora Adjunto da Universidade Estadual de Maringá (UEM). Maringá, PR, Brasil. E-mail: casales@uem.br.

${ }^{2}$ Enfermeira. Discente do Programa de Pós-graduação em Enfermagem, nível Mestrado. Maringá, PR, Brasil. E-mail: kellyiap.enf@gmail.com.

${ }^{3}$ Enfermeira, Mestre em Enfermagem. Maringá, PR, Brasil. E-mail: kesleyreticena@hotmail.com.

${ }^{4}$ Enfermeira, Mestre em Enfermagem. Discente do Programa de Pós-graduação em Enfermagem, nível Doutorado. Maringá, PR, Brasil. E-mail: julia.wakiuchi@gmail.com.

${ }^{5}$ Enfermeira, Doutora em Filosofia da Enfermagem. Professora Associada da Universidade Estadual de Maringá. Maringá, PR, Brasil. E-mail: soniasilva.marcon@gmail.com.

\section{RESUMO}

Objetivou-se compreender como a pessoa com câncer percebe a presença ou a ausência do familiar enquanto realiza tratamento longe do lar. Pesquisa fenomenológica heideggeriana, realizada com 11 pessoas em tratamento antineoplásico, hospedadas em uma casa de apoio. Os dados foram coletados no período de junho a setembro de 2013, por meio de entrevistas em profundidade. As temáticas ontológicas suscitadas foram: estreitando laços com a presença familiar, reconhecendo a necessidade da presença familiar e revelando a importância dos companheiros de tratamento na ausência familiar. O estudo desvelou que as pessoas com câncer reconhecem que a presença de seus familiares ameniza a situação vivenciada, pois estes, de maneira autêntica, as acolhem e lhes prestam os mais íntimos cuidados. Concluiu-se que a presença familiar diminui a distância do lar e melhora o enfrentamento da doença. Na ausência dos familiares, os pacientes encontram, nos companheiros da casa de apoio, amparo e conforto.

Descritores: Família; Cuidadores; Neoplasias; Apoio Social; Enfermagem.

\section{ABSTRACT}

The objective of this study was to understand how people with cancer perceive the presence or absence of relatives while undergoing treatment away from home. A Heideggerian phenomenological research was conducted with 11 people undergoing antineoplastic treatment and lodged in a support house. Data were collected between June and September 2013, by means of in-depth interviews. The following ontological themes were originated: strengthening relationships with the family presence, recognizing the need for family presence and revealing the importance of treatment companions in the family absence. The study revealed that people with cancer recognize that the presence of relatives eases the situation experienced, since they authentically embrace and provide them with more intimate care. In conclusion, the family presence reduces the distance from home and improves the coping with the disease. In the absence of relatives, patients find support and comfort in companions from the support house.

Descriptors: Familia; Caregivers; Neoplasms; Social Support; Nursing.

\section{RESUMEN}

Se objetivó comprender la percepción del paciente con cáncer sobre la presencia o ausencia familiar mientras recibe tratamiento lejos del hogar. Investigación fenomenológica heideggeriana, realizada con 11 pacientes en tratamiento antineoplásico hospedados en casa de apoyo. Datos recolectados entre junio y setiembre de 2013 mediante entrevistas en profundidad. Las temáticas ontológicas suscitadas fueron: estrechando lazos con la presencia familiar, reconociendo la necesidad de la presencia familiar, y revelando la importancia de los compañeros de tratamiento en la ausencia familiar. El estudio reveló que los pacientes con cáncer reconocen que la presencia familiar ameniza la vivencia de la situación, pues ellos, de manera auténtica, los acogen y les prestan los cuidados más personales. Se concluye en que la presencia familiar minimiza la distancia del hogar y mejora el afrontamiento de la enfermedad. En ausencia de familiares, los pacientes encontraron amparo y comodidad en los compañeros de la casa de apoyo.

Descriptores: Family; Cuidadores; Neoplasias; Apoyo Social; Enfermería. 


\section{INTRODUÇÃo}

O câncer representa um enorme desafio para os cuidados de saúde, pois o mesmo traz mudanças importantes no modo de viver dos indivíduos acometidos e na sociedade em geral, por impor desde gastos financeiros significativos até a sobrecarga emocional do paciente e familiares ${ }^{(1)}$. Tais alterações fazem com que os doentes de câncer convivam com sentimentos de sofrimento e angústia, os quais Ihes afetam em todas as dimensões como ser humano ${ }^{(2)}$. Ante tais evidências, a atenção dispensada aos aspectos psicossociais do câncer e seus efeitos no individuo é tão importante quanto o tratamento da doença em si.

O avanço no que tange a terapias antineoplásicas, suscitou diferentes perspectivas à pessoa com câncer, que atualmente tem a possibilidade de ser tratado com novas opções terapêuticas e abordagens sistêmicas que melhoram sua sobrevida ${ }^{(1,3)}$. Entretanto, a conjuntura apresentada não exclui as ansiedades e inquietações vivenciadas nas diferentes fases da doença, principalmente no itinerário de busca por tratamentos e cuidados $^{(4)}$. É justamente nestes momentos que a família e equipe de saúde passam a ter um papel determinante na vida das pessoas com câncer, visto que seu suporte e amparo são, muitas vezes, os únicos recursos disponíveis a esses indivíduos nos momentos de dificuldade ${ }^{(5)}$.

Destaca-se que, em alguns casos, as pessoas adoecidas de câncer necessitam de deslocamento a outro município para a realização do tratamento antineoplásico e, com frequência, não podem contar com o acompanhamento de um ente querido. Nestas situações, elas experienciam uma temporalidade subjetiva, que se traduz nos sentimentos avivados por estarem longe de seus entes próximos ${ }^{(6)}$. Além disso, grandes distâncias do local de tratamento podem ser um impeditivo para adesão dos doentes a terapias antineoplásicas, o que suscita a criação e implementação de estratégias que favoreçam a continuidade do tratamento(7). É neste contexto que a manutenção de casas de apoio em regiões que são referência para o tratamento oncológico merece a atenção e incentivo, pois, dentro dessa vertente de cuidados, pauta-se a possibilidade de inúmeras pessoas darem seguimento a seu tratamento e, vivenciarem este momento de maneira mais amena, principalmente quando é possibilitado que os familiares permaneçam com os doentes.

Diante das mudanças que o câncer acarreta, a enfermagem precisa conhecer as interações e vínculos que se formam entre os familiares e pacientes, de modo a se tornar cada vez mais eficaz no fornecimento de suporte a ambos, fortalecendo as possibilidades de cuidado, visto que, ao estar distante de sua família, o doente, na maioria das vezes, vive a potencialização de seu sofrimento e ansiedade, o que gera sensação de impotência em seus familiares ${ }^{(8)}$. Destarte, o adoecimento por câncer repercute no desejo por um cuidado distinto e pessoalizado, com espaço para o compartilhamento de sentimentos e apoio emocional ${ }^{(9)}$. Neste sentido, destaca-se a importância da presença familiar no acompanhamento e cuidado ao paciente com câncer, visto que a família pode ser uma aliada na manutenção de sentimentos positivos e na melhoria da qualidade da assistência ${ }^{(10)}$.

Com base nestas constatações e nas observações em campos de prática direcionadas a pessoas com câncer que realizam seu tratamento longe do lar, questiona-se: Qual o significado para a pessoa com câncer em ter ou não a presença de um familiar ao realizar tratamento fora de seu domicílio? Tal inquietação justifica-se pela necessidade de os profissionais de saúde reconhecerem o que as pessoas com câncer consideram importante no trilhar de sua terapêutica e, deste modo, possam realizar uma assistência pautada na escuta e entendimento das reais demandas apresentadas pelos doentes $^{(11)}$.

Assim, este estudo teve como objetivo compreender como a pessoa com câncer percebe a presença ou a ausência do familiar enquanto realiza tratamento longe do lar.

\section{METODOLOGIA}

Trata-se de um estudo fundamentado na fenomenologia existencial de Martin Heidegger. Este referencial possibilita a reflexão e maior qualidade na assistência de enfermagem, pois, por meio da investigação fenomenológica, as necessidades dos doentes com câncer podem ser amplamente conhecidas, e assim, abrir novos caminhos para o cuidado(12).

O estudo foi desenvolvido junto a indivíduos em tratamento antineoplásico hospedados em uma casa de apoio na região noroeste do Paraná. Esta constitui-se em uma entidade social beneficente, sem fins lucrativos, que provê suporte a pessoas residentes em outros municípios pertencentes à $15^{a}$ Regional de Saúde do Estado do Paraná e que realizam tratamento radio ou quimioterápico na cidade sede da Regional de Saúde. Tal entidade oferece às pessoas com câncer, hospedagem, transporte, alimentação e entretenimento durante o período de realização do tratamento, com o intuito de 
promover qualidade de vida e prevenir agravos. Cabe salientar que a instituição possui um veículo que faz o transporte dos doentes até o local de realização dos tratamentos.

Foi adotado como critério de inclusão dos sujeitos ter realizado pelo menos metade do tratamento previsto, conferindo ao doente a vivência da presença ou da ausência do familiar cotidianamente enquanto realizava o tratamento longe do lar.

As entrevistas foram realizadas a partir de visitas à casa de apoio em diferentes dias e horários, no período de junho a setembro de 2013. Duas pesquisadoras realizaram as visitas, sendo que uma delas procedia a entrevista com o doente, enquanto a outra interagia com os familiares e com as outras pessoas presentes na instiuição. Tal conduta intencionou garantir maior liberdade aos depoentes e fidedignidade de suas respostas frente à questão norteadora: Como está sendo para você ter ou não a presença de um familiar enquanto faz o tratamento longe do lar? Utilizou-se ainda um roteiro semiestruturado com dados sociodemográficos, para caracterização dos sujeitos do estudo.

A análise dos dados foi feita concomitantemente as entrevistas, sendo interrompida a inclusão de novos participantes no estudo a partir do momento em que o fenômeno foi sendo desvelado, as inquietações dos pesquisadores respondidas e o objetivo do estudo alcançado. As entrevistas foram transcritas na íntegra, com posterior realização de leituras atentas de cada depoimento, a fim de separar os trechos ou unidades de sentido que se mostravam fundamentais à significação concedida pelos depoentes. Posteriormente, foram analisadas as unidades de sentido de cada depoimento e realizada a seleção fenomenológica da linguagem de cada sujeito $^{(13)}$.

Resultante deste processo, surgiram as temáticas ontológicas: "estreitando laços com a presença familiar", "reconhecendo a necessidade da presença familiar", "revelando a importância dos companheiros de tratamento na ausência familiar". Sua discussão fundamentou-se no referencial heideggeriano e em autores que abordam a temática.

Como se trata de uma pesquisa que envolve seres humanos, foram observados os aspectos éticos disciplinados pela Resolução 466/2012, do Conselho Nacional de Saúde - Ministério da Saúde, com aprovação do Comitê Permanente de Ética em Pesquisas com Seres Humanos da Universidade Estadual de Maringá, mediante Parecer $n^{\circ} 448.228 / 2013$. A participação no estudo se deu somente após a assinatura, em duas vias, do termo de consentimento livre e esclarecido e o anonimato dos participantes foi garantido, sendo seus nomes substituídos por um código de letras seguido por um número indicativo da ordem da entrevista, pelas letras $F$ ou $M$ indicando sexo feminino ou masculino, $e$ um ultimo numero indicativo da idade dos participantes (E-1, sexo, idade/ E-2, sexo, idade/ E-3, sexo, idade...).

\section{RESULTADOS}

Os 11 participantes do estudo tinham idades entre 40 e 96 anos, sendo sete do sexo feminino, sete casados, dois viúvos e dois separados. Todos tinham filhos, entretanto dois moravam sozinhos, três deles moravam somente com o cônjuge, quatro moravam com o cônjuge e com os filhos e dois moravam somente com os filhos. Quanto ao grau de escolaridade, um não era alfabetizado, oito concluíram o ensino primário, um concluiu o ensino médio e um tinha ensino superior incompleto.

Durante o acompanhamento para o tratamento antineoplásico longe do lar, enquanto hospedados na casa de apoio, três foram acompanhados por filhos, um por filhos e nora, três pelo cônjuge e quatro não recebiam acompanhamento de familiar.

A seguir, são apresentadas as percepções quanto à presença ou ausência do familiar ao realizar o tratamento longe do lar, tomando por base a linguagem dos 11 depoentes.

\section{Estreitando laços com a presença familiar}

Entre os doentes que contavam com a presença de um acompanhante familiar durante a realização do tratamento antineoplásico longe do lar, foi destacado o prazer em ter ao seu lado alguém da família durante este processo, o que despertava sentimentos positivos, e possibilitava inferir que o afeto e a atenção dedicados ao doente contribuem para seu bem-estar.

[...] Você vê os familiares tudo junto comigo, ali guardando, cuidando de mim, bem cuidado, como se eu fosse uma criança recém-nascida ali, bajuladinha assim [...] gente receber cuidado da família é a coisa mais gostosa que existe. [...] Muito gostoso. Gostoso mesmo. Muito bom. [...] Tudo quanto é cantinho eu tenho um lá, de ouvidinho escutando a velha. A velha está aqui. É minha filha, muito bom. Acho que a coisa melhor que existe no mundo é a atenção da pessoa. A pessoa que os outros dão atenção, ela é uma pessoa feliz. [...] Eu sou uma pessoa muito feliz, graças a Deus. [...] Junta todos os meus filhos, meus netos, minhas noras, meus 
bisnetos, tudo, a família completa. É a coisa melhor que existe. Muito melhor. Nossa. É bom demais, menina! Muito bom (E-1, mulher 75 anos).

É bem legal mesmo, minha sobrinha cuida bem, graças a Deus. É uma filha mesmo, que eu só tenho uma, então, com ela, eu conto duas, as filhas que eu tenho ( $E-2$, mulher 68 anos).

Em um vínculo ainda mais profundo, constatou-se a formação de uma relação de cumplicidade e intimidade, que se estabeleceu com o cuidado prestado devido à doença e ao tratamento, bem como pela aproximação fortalecida em decorrência de estarem longe de seus lares.

[...] É imprescindível para mim, não tem mais como o que eu possa explicar, porque para estar com uma pessoa estranha, eu nunca estive como acompanhante, $e$ eu não sei como me sairia. É eu e minha esposa e pronto. Portanto, é a família, acima de tudo para mim é a família. Então eu sou acompanhado pela minha esposa, 38 anos de casado e eu me sinto bem, é o que me dá força [...] é indispensável, porque eu me sinto ancorado, entendeu. É demais. Eu não sei se você quer mais algum adendo, mais algum tipo de explicação, porque como me expressar, é ... A gente se sente ... Já estamos longe do lar, já estamos com esse pequeno ... Porque para mim é um problema, então a gente, tanto eu como ela, eu acho que nós fazemos é um só, eu e minha acompanhante é um só, ela já sabe de cor e salteado o que eu preciso, e que às vezes eu nem preciso pedir, ela já sabe, então, os horários da minha medicação, tudo isso, como eu gosto de tomar o banho, como eu me porto, a roupa que eu gosto de vestir, roupa solta, entendeu? Eu acho que seria difícil encontrar alguém que não da família que realizasse esse mesmo papel. É bem difícil. (E-3, homem 72 anos).

\section{Reconhecendo a necessidade da presença familiar}

O doente com câncer enfrenta muitas limitações impostas pela doença. A presença familiar, nesse momento, é reconhecida pelo indivíduo como necessária no apoio às dificuldades encontradas.

[...] Eu acho que é maravilhoso a gente ter uma família junto, a gente precisa de tudo, a gente estando doente não decide nada, está certo? Eu acho que é bom para mim e é bom para minha família toda, eu me sinto tranquila sabe, me sinto segura. Eu acho que é certo. Para mim, está sendo bom, está sendo bom, uma companhia boa, tem confiança, fico contente. Espero que todas as pessoas que estão doentes sejam felizes, do mesmo modo, com a família (E-4, mulher 96 anos).

[...] Com alguém da minha família, que é minha esposa, eu me sinto dentro de casa. Porque, aqui, é um lar para mim. Aqui, eu tenho tudo, e as pessoas gostam muito de mim. É, não tem aonde eu tirar nada, tudo o que eu tenho é deles, e o que é deles é meu, comem lá, e eu não estou lá na mesa por causa da mão, porque com uma mão só não dá, a mulher (esposa) traz a minha comida, come aqui, traz água, encosta aí, pega a cadeira, e eu gosto daqui e me sinto tranquilo, chego aqui, é outro ar. Então é uma família que a gente tem. Sinto-me realizado, é o caso se for, eu não tenho ninguém a não ser ela aqui. Tem meus filhos, os parentes, mas parente nunca é igual à família [...] eu tinha dificuldade de ir ao banheiro e, aqui, minha esposa ajuda, aí eu vou devagarzinho, devagarzinho, sento na cadeira, tira a fralda ali, põe no cesto, aí eu vou para o banheiro e, quando acabo, ela vai ali, me levanta da cadeira, me ajuda a ensaboar, aí ela me enxuga, me deixa sequinho, troca eu e, no mais, é isso. $E$ a vantagem é que eu tenho ela [...] (E-5, homem 58 anos).

Constatou-se também a manifestação de gratidão e de contentamento em ter a presença de um familiar, por ser este um auxílio nas mais diversas limitações que os doentes passam a vivenciar, quer seja envolvendo decisões, aspectos rotineiros e básicos do dia a dia, como até mesmo a permanência na casa de apoio para a realização do tratamento. O reconhecimento da necessidade dessa presença pode ser ainda maior quando o doente relaciona a dependência familiar com a continuidade de sua vida:

[...] Graças a Deus, está muito bem, porque se não fosse ela (filha), sozinho, aqui, não podia ficar, já poderia ter 'viajado para o Japão' já... Mas graças a Deus, estou vivendo ainda mais um dia por causa dela e, graças a Deus, que pelos outros (filhos) eu não estava aqui mais não. [...] e graças a essa que está comigo, graças a Deus, pelo o que está se passando comigo, eu estou sentindo muito bem (E-6, homem 71 anos).

[...] Graças a Deus, eu me sinto muito feliz da minha vida, [...] porque eu estou longe da minha família e lá da minha casa, então tem a minha filha que fica cuidando de mim, graças a Deus. Se não fossem eles, eu não estaria aqui. Se não fossem eles, eu já 'teria ido para baixo do chão'. Por isso que eu falo que eu me sinto 
feliz, me sinto contente, porque meus filhos estão junto comigo ( $E-7$, homem 63 anos).

\section{Revelando a importância dos companheiros de tratamento na ausência familiar}

$\mathrm{Na}$ ausência da companhia de uma pessoa da família, os doentes da casa de apoio se unem, ajudando uns aos outros, o que faz nascer uma amizade, a qual ameniza o fato de estarem longe do lar.

[...] Ah, ficar longe de casa é ruim, mas tudo na vida a gente acostuma, não é?! Agora, ficar assim sozinha, eu fico sozinha só quando fico dentro do quarto, mas sem ter alguém da minha família eu acho meio ruim, não tem ninguém para conversar, mas ainda bem que eu tenho meus amigos que estão nos outros quartos. Então, bola para frente! A gente acostuma, já acostumei nessa batalha (E-8, mulher 43 anos).

Até mesmo aqueles que afirmam já estar acostumados com a situação de solidão, e não têm problemas quanto a este fato, revelam que gostam da presença dos amigos na casa de apoio.

[...] Aqui, para mim, eu me sinto como na minha casa. $A$ gente tem as vizinhas aqui e eu estou me sentindo bem graças a Deus. A gente fica longe de casa, mas vai fazer o quê? Tem que se conformar, e a gente se dá muito bem aqui. Tem as meninas aqui que são uns amores. $E$ eu estava sozinha aqui, aí, ela falou: não, desliga a televisão aqui, e vai assistir lá na sala, tem a grandona lá, vem ver a televisão aqui. Eu ficava quieta aqui, ficava sozinha. Mas eu estou acostumada sozinha, agora quem não é acostumada sente muita falta sim; agora, eu não. Melhor ter alguém, mas se não tem... Não tenho o que reclamar, já sou acostumada sozinha então. Mas tem uma aqui que fala que sente falta da casa, do marido e dos filhos, coitada. Porque ela deixou criança, mas eu falei para ela: pensa que nós estamos juntas para te dar força. Mas ela está gostando (E-9, mulher 68 anos).

[...] Não tem nada a ver, porque lá em casa eu fico sozinha também, sozinha e com Deus. Então, não tem ninguém. Venho aqui e pronto, mas, aqui, ainda é melhor, arranjo os amigos aqui, aí é muito bom. Você viu, eu estava dormindo até agora, igual lá na minha casa. Para mim, não faz diferença (E-10, mulher 60 anos).

Em outro relato revela-se que, além de não possuir a presença familiar durante a permanência na casa de apoio, a depoente não se relacionava com nenhum outro colega da instituição para amenizar as angústias do momento vivenciado, visto que não havia mais ninguém hospedado na casa naquele momento. Entretanto ela esboçava o desejo de ter alguém para lhe fazer companhia e proporcionar-lhe momentos de distração.

[...] Para mim, faz falta, eu acho que significaria bastante uma pessoa aqui comigo, se pudesse ter alguém, se pudesse ter alguém que ficasse comigo, mas, como não tem, a gente fica sozinha, mas acho que ajudaria bastante. Ter um companheirismo, ter uma pessoa para conversar, à noite, não sentiria tão sozinha, e aí às vezes os horariozinhos que a gente tem, sair um pouco, desparecer um pouco. Eu acho que seria bem significativo alguém junto. Se tiver condições, quem tem, eu acho é ... que seria bom (E-11, mulher 40 anos).

\section{DISCUSSÃO}

O Dasein (ser-aí) constitui-se ser-no-mundo por meio de sua vivência no mundo, uma vez que não está simplesmente lançado em um espaço físico ${ }^{(14)}$. Ser-nomundo é uma condição intimamente ligada a ser-comos-outros, porque este se faz próximo dos entes com quem ele compartilha o mundo à sua volta e, mesmo que permaneça só em seu mundo circundante, o sercom constitui-se como uma característica ontológica do ser-no-mundo ${ }^{(15)}$. Logo, o membro da família, enquanto ser-no-mundo de um ente com câncer, relaciona-se de modo a ser-com este familiar doente.

Nesta conjuntura, faz-se necessário considerar que, na analítica heideggeriana, o ser-com manifesta-se de dois modos distintos, os quais transitam entre a ocupação e a preocupação. Na ocupação, deixa-se guiar pela indiferença e pela negligência no trato com outros entes ao seu redor, enquanto que, na preocupação, ele estabelece o modo de correlação e, por um privilégio ôntico-ontológico, torna-se ser-com-os-outros de uma forma autêntica(16). Sob este pensar, apreendeu-se, pela linguagem dos usuários, que a família, em seu modo de ser, revela-se como cuidadora autêntica ao assumir e compartilhar junto a seu ente querido a facticidade do tratamento do câncer, com o intuito de amenizar seu sofrimento.

Relativo a esta questão, salienta-se que a atenção concedida pela família, por intermédio da escuta e da cumplicidade com o doente, configura-se como a solicitude, que é uma característica existencial do homem em seu sendo-no-mundo(14). Quando os familiares exercem as funções do cuidado de seu ente 
adoecido, fazem-no como uma forma de retribuição e, muitas vezes, ao assumir tal cuidado, amenizam suas angústias e sofrimento frente à situação vivenciada pelo familiar doente ${ }^{(17)}$. Esta preocupação é reconhecida no discurso de E-4, que percebe a presença familiar como algo benéfico não só para ele, mas como algo que contribui para o bem estar de todos os envolvidos no cuidado.

Destaca-se que, por meio da afetividade, o homem se abre e deixa que os outros seres venham ao seu encontro, o que faz emergir a possibilidade de poder tocar e ser tocado. Assim, ao ocupar-se da alimentação e do vestuário de seu familiar doente, desvela-se um modo de preocupação(14). Estes aspectos se revelam na linguagem dos depoentes à medida que explanavam sobre o apoio e carinho recebidos dos familiares em um momento tão difícil de suas vidas.

Quando a família consegue acompanhar o doente nos momentos de consulta médica e tratamentos ambulatoriais, além de auxiliar nos cuidados básicos de alimentação e higiene, a mesma transmite segurança e solidariedade ${ }^{(8)}$. Reitera-se ainda que, em virtude da presença familiar, os doentes sentem-se menos constrangidos quando recebem os cuidados de um ente próximo, e expressam gratidão, sobretudo quando deparam-se com a possibilidade de sua morte, que se apresenta para a maioria dos doentes submetidos a tratamentos antineoplásicos ${ }^{(18)}$.

O homem é um ser-no-mundo que existe sempre em relação com algo ou alguém e, neste estado, compreende as suas experiências, estabelece significado próprio aos objetos e entes em seu mundo e dá sentido à sua existência ${ }^{(14)}$. Nesse sentido, a análise do ser-nomundo deve levar em consideração todo o contexto histórico, social e individual por ele vivenciado, que influencia seu modo de interagir e relacionar-se com o mundo ${ }^{(19)}$.

Quando o ser vivencia a doença, mas possui alguém por perto em quem pode confiar e compartilhar de seus sentimentos, sente-se seguro e enfrenta melhor as dificuldades impostas pelo tratamento ${ }^{(12)}$. Por outro lado, ao ter que enfrentar sozinho e distante do seio familiar um tratamento enredado em vicissitudes, a pessoa sente-se perdida perante o mundo. Na fala de E-11, pode-se perceber o sentimento de solidão expresso por ela ante a ausência de um ente querido que lhe pudesse prestar apoio, carinho e, particularmente, companhia ante a facticidade vivenciada.

Neste prisma, não somente as pessoas, mas as estruturas da casa contribuem para o bem-estar dos doentes com câncer. Os utensílios ou objetos não são uma realidade simplesmente subsistente, mas estão disponíveis para um uso determinado, como algo que o homem dispõe para viver no mundo ${ }^{(14)}$. A maneira como o ser-no-mundo se relaciona e descobre os utensílios se dá pela ocupação, intermediada pelo seu manuseio e uso $^{(20)}$. Vale ressaltar o caso de E-10, que se sentia como em sua própria casa pelo fato de poder dormir e estar à vontade. Ela ocupava-se de um utensílio, que, assim como em seu lar, contribuía para o seu conforto.

Nesse sentido, a manutenção de casas de apoio em regiões que são referência para o tratamento antineoplásico merece atenção e incentivo, pois, nessa vertente de cuidados, inúmeras pessoas conseguem dar seguimento a seu tratamento e vivenciar este momento de maneira mais amena, especialmente quando é possibilitado que os familiares permaneçam com os doentes.

Ademais, a doença oncológica traz muitas transformações que afetam as relações familiares, já que, além das pessoas próximas sofrerem por vê-los fragilizados, os próprios doentes são impactados pela angústia dos que o acompanham, o que leva à necessidade de uma reorganização para atender às novas necessidades de cuidado(17,21). Assim, a interação existente entre os familiares deve ser considerada nas ações de cuidado, uma vez que ambas as partes são influenciadoras no processo de saúde e doença ${ }^{(22)}$. Esta importância foi apreendida na linguagem dos sujeitos entrevistados frente ao desafio da luta contra o câncer e intensificada por terem que sair de seus lares em busca de tratamento. Constatou-se ainda que, na disposição de estar-com seus entes queridos durante sua facticidade existencial, os familiares revelaram-se como cuidadores autênticos, ao transmitir ao doente, acolhimento e a impressão de não estar-só em sua peregrinação.

\section{CONSIDERAÇÕES FINAIS}

O estudo permitiu compreender que os doentes com câncer que precisam se deslocar para realizar o tratamento longe de seus lares reconhecem a importância da presença da família neste momento, bem como expressam gratidão ao terem um ente querido os acompanhando durante os percalços da doença e tratamento. Tornou-se evidente que a atenção recebida da família possibilita a diminuição da distância do lar, o que leva ao enfrentamento de sua jornada com menos sofrimento. Além disso, foi possível reconhecer que, quando a família não pode estar presente, os 
companheiros da casa de apoio, que vivenciam situações semelhantes, são fonte de apoio e conforto, manifestando solicitude nos momentos de dificuldade.

De tal forma, por meio deste estudo, é possível reafirmar que as casas de apoio a doentes com câncer devem não somente acolher o ente adoecido, mas sua família, que poderá contribuir na manutenção do bem

\section{REFERÊNCIAS}

1. Drageset J, Corbert A, Selbaek G, Husebo BS. Cancer-Related Pain and Symptoms Among Nursing Home Residents: A Systematic Review. J Pain Symptom Manage. 2014 Oct [citec 2014 Oct 19]; 48(4):699-710.

2. Trill MD. Anxiety and sleep disorders in cancer patients. EJC Suppl. [Internet]. 2013. [cited 2014 Set 22]; 11(2):216-24. Available from: http://www.ejcancersupplements.com/article/S13596349(13)00010-4/pdf.

3. Morton LM, Swerdlow AJ, Schaapveld M, Ramadan S, Hodgson DC, Radford J, et al. Current knowledge and future research directions in treatment-related second primary malignancies. EJC Suppl. [Internet]. 2014. [cited 2014 Set 22]; 12(1):5-17. Available from:

http://www.sciencedirect.com/science/article/pii/S13596349140 00032 .

4. Northouse LL, Katapodi MC, Schafenacker AM, Weiss D. The Impact of Caregiving on the Psychological well-being of family caregivers and cancer patients. Semin. oncol. nurs. 2012; 28 (4):236-45.

5. Kvale K. Synnes O. Understanding cancer patients' reflections on good nursing care inlight of Antonovsky's theory. Eur. j. oncol. nurs. 2013; 17(6):814-9.

6. Sales CA, Almeida CSL, Silva JDD, Silva VA, Waidman MAP. Qualidade de vida sob a ótica de pessoas em tratamento antineoplásico: uma análise fenomenológica. Rev. eletrônica enferm. [Internet]. 2011. [cited 2013 Nov 20]; 13(2):250-8. Available from: http://dx.doi.org/10.5216/ree.v13i2.12654.

7. Borda $A$, et al. Tiempo de viaje y participación en el cribado del cáncer de mama

8. Vestena Zillmer JG, Schwartz E, Burille A, et al. Vínculos de los Clientes oncológicos y familiares: una dimensión para ser observada. Enfermería global. 2012; 11(25):37-44.

9. Oliveira VC, Refshauge KM, Ferreira ML, Pinto RZ, Beckenkamp PR, Negrao Filho RF, et al. Communication that values patient autonomy is associated with satisfaction with: a systematic review. J. physiother. 2012; 58 (4):215-29. en una región de alta dispersión poblacional. Gac Sanit. 2011;25(2):151-56.

10. Faber V, Rosanelli CP, Loro MM, Kolankiewicz ACB, Piovesan S, Leite MT. Percepções de doentes crônicos acerca do cuidado prestado por familiares. Ciênc Cuid Saude. 2012; 11(3):565-72. 11. Chochinov HM. Dignity in Care: Time to Take Action. J. pain symptom manage. 2013;46(5):756-9.

12. Baptista PCP, Merighi MAB, Freitas GF. El estudio de la fenomenología como una vía de acceso a la mejora de los cuidados de enfermeira. Cultura de los Cuidados. 2011;15(29):915.

13. Josgrilberg RS. A fenomenologia como novo paradigma de uma ciência do existir. In: Pokladek DD, organizadora. A fenomenologia do cuidar: prática dos horizontes vividos nas áreas de saúde, educacional e organizacional. São Paulo: Vetor; 2004. p. 31-52.

14. Heidegger M. Ser e tempo. 6 ed. Petrópolis: Vozes; 2012. 15. Silva EB. Heidegger e a destruição do conceito metafísico tradicional de existência. Inquietude. [Internet] 2012 [cited 2013 nov 20]; 3 (1):52-73. Available from:

http://www.inquietude.org/index.php/revista/article/view/112. estar do sujeito como um todo e, a partir de um olhar ampliado ao seu cuidado, ser-com de forma autêntica. A partir desta compreensão por parte dos profissionais de saúde, é possível promover uma assistência mais humanizada, que seja pautada na solicitude e nas necessidades dos doentes com câncer que precisam se deslocar em seu processo de tratamento.

16. Martins Filho JRF. Heidegger e a concepção de "outro" em Ser e Tempo. R aproximação. [Internet] 2010 [cited 2013 Nov 20];1(3):56-76. Available from:

http://www.ifcs.ufrj.br/ aproximacao/volume3.html. 17. Moreira de Souza R, Turrini RNT. Terminally Ill Cancer Patient: Caregiver Burnout. Enferm. glob. [Internet]. 2011 [cited 2013 Nov 10]; 10(22):1-13. Available from: http://dx.doi.org/10.4321/S1695-61412011000200013. 18. Lafaurie MM, Castiblanco BDR, González Díaz JM, Jiménez Tamayo DM, Moreno LB, Ramírez LP et al. Mujeres en tratamiento de cáncer, acogidas por un Albergue de Apoyo: circunstancias y perspectivas de cuidado de Enfermería. Rev. colomb. enferm.; 2009;4(4):61-72.

19. Pascal J. Phenomenology as a Research Method for Social Work Contexts: Understand the Lived Experience of Cancer Survival. Current: Scholarship in the Human Services [Internet]. 2013 [cited 2014 nov 25]; 12(1):1-20.

20. Mendonça ES. O útil e a obra de arte em Marx e Heidegger. Griot - Revista de Filosofia. [Internet]. 2010 [cited 2013 Nov 02];2(2):74-81. Available from: http://journaldatabase.org/articles/util_obra_arte_marx_heidegg er1.html.

21. Penner JL, McClement S, Lobchuk M, Daeninck P. Family Members' Experiences Caring for Patients With Advanced Head and Neck Cancer Receiving Tube Feeding: A Descriptive Phenomenological Study. Journal of Pain and Symptom Management 2012; 44(4):563-571. Available from: http://www.sciencedirect.com/science/article/pii/S08853924120 01571.

22. Alarcón AM, et al. Development of a functional model of nursing care in cancer. Invest. Educ. Enferm. [Internet]. 2014. [cited 2014 Out 12]; 32(2):206-215. Available from: http://www.redalyc.org/articulo.oa?id=105231325003.

Artigo recebido em 10/12/2013. Aprovado para publicação em 01/07/2014. Artigo publicado em 31/03/2015. 